\title{
UV/UV step-curing of optically clear acrylate adhesives for mobile devices
}

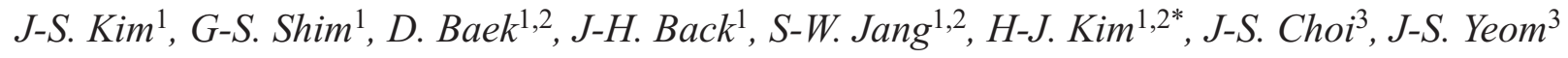 \\ ${ }^{1}$ Laboratory of Adhesion and Bio-Composites, Program in Environmental Materials Science, Seoul National University, \\ 08826 Seoul, Republic of Korea \\ ${ }^{2}$ Research Institute of Agriculture and Life Sciences, College of Agriculture and Life Sciences, Seoul National University, \\ 08826 Seoul, Republic of Korea \\ ${ }^{3}$ LMS Co., Ltd., 177-09 Pyeongtaek, Republic of Korea
}

Received 23 February 2019; accepted in revised form 23 April 2019

\begin{abstract}
In order to overcome the issues of rework and height difference in the manufacturing of smart devices, UV/UV stepwise curing was conducted on acrylate-based optically clear adhesives. Photo differential scanning calorimetry was used to confirm the results of curing of samples that were processed both with and without acrylic acid, over a range of UV light exposure times for a primary curing process. The samples processed at $0.6 \mathrm{~J} / \mathrm{cm}^{2}$ of UV energy with and without acrylic acid showed the highest amount of residual monomers after primary curing. The amount of residual monomers observed in primary-cured samples decreased as the amount of UV light energy increased, from 0.9 to $1.5 \mathrm{~J} / \mathrm{cm}^{2}$. After secondary curing, only the samples cured at $0.6 \mathrm{~J} / \mathrm{cm}^{2}$ showed small amounts of residual monomers, while the samples exposed to other UV energies showed very few residual monomers, implying that these samples were completely cured during the secondary curing step. Adhesion properties were evaluated using peel and tack tests, while the viscoelastic properties of the samples were confirmed by dynamic mechanical analysis. Our results indicate that uniform physical properties were achieved after secondary curing. The effects of stepwise curing are demonstrated by the difference in gel fractions determined after primary and secondary curing.
\end{abstract}

Keywords: adhesion, optically clear adhesives, UV curing, photo-differential scanning calorimetry, mechanical properties

\section{Introduction}

Optically clear adhesives (OCAs) have recently been applied in various industrial applications $[1$, $2]$, such as the use of acrylic OCAs for color filters in liquid crystal displays [3]. Acrylic pressure-sensitive adhesives (PSAs) blended with titanium oxide [4], hafnium carboxyethyl acrylate [5], and zirconium carboxyethyl acrylate [6] have also been studied as OCAs for applications. These have a high refractive index, which can contribute to clearer images on a display. Acrylic PSAs can be obtained through various polymerization processes such as the emulsion [7-9], solvent-type [10], water-borne [11], and radiation polymerization techniques [5]. However, much attention has recently been devoted to the use of more environmentally friendly processes, such as the ultraviolet (UV) technique. The crosslinking mechanism involved in UV curing has been thoroughly investigated $[12,13]$. PSAs may be produced using UV-curing systems through exposure to UV light in the presence of a suitable photo-initiator, which induces radical photopolymerization and promotes the conversion of the monomer to oligomers. This process has many advantages (e.g., it is solvent-free and has a low volatile organic compound content), which are important in industries 
such as coating, painting, and adhesive production [14-16].

In the assembly process for mobile devices, if there is an issue after attaching the adhesive to the device, it is often necessary to discard the entire module. This is becoming a key issue, because these modules are expensive and the process of remanufacturing the modules becomes inefficient. In order to overcome this problem, a stepwise curing procedure for OCAs was developed in this study. Previously, stepwise curing has been implemented as UV/thermal dual curing to overcome limitations related to the thickness in UV curing [17]. However, this approach can result in thermal damage of the module and is therefore of limited applicability in smart device fabrication. In contrast, stepwise curing in this study was conducted by employing two UV curing steps, primary and secondary, in different ways. Before secondary curing, the PSA exhibits relatively high softness, which can enhance properties related to reworking. In the case that a worker makes a mistake or follows a process incorrectly, reworking can be performed before secondary curing. Moreover, a low modulus prior to secondary curing allows OCAs to overcome the height difference of the frame. After the assembly is finished, a worker can proceed with secondary curing to enhance the adhesion properties of the OCA, and the final step-cured OCA can exhibit the properties appropriate for device applications.

Stepwise curing can be realized using methyl methacrylate (MMA) with OCA pre-polymers during the synthesis of the adhesive. MMA belongs to the methacrylate group of compounds that react slowly compared to those in the acrylate group. The black light (BL) lamp, which provides very weak UV light energy, is also employed for primary curing. In general, the properties of acrylic PSAs vary according to the mechanical and chemical methods employed, e.g., adjusting the amount or type of blended tackifiers, the extent of the main chain cross-linkage [18], and also the type of cross-linking system [19]. Therefore, it is important to understand the differences in the chemical and physical properties of the system, and the possibility of complete curing when the crosslinking process is divided into two steps.

Acrylic adhesives have often been used as OCAs owing to their fast UV curability, clarity of the cured adhesive, and excellent economical aspects. These adhesives usually contain an acidic component, such as acrylic acid (AA), to improve cohesion and supply the remaining reaction sites with a curing agent [20]. However, if this acidic component is added to the OCA, it could corrode the metallic circuits of the device underneath [21-23]. Therefore, the concept of non-acid curing is emerging as an important aspect of OCA development. It is necessary to study acrylic PSAs without AA along with the possibility of stepwise curing for their possible application in OCAs. There are currently no published studies on either OCAs without an acidic component or the performance of stepwise UV/UV curing. Accordingly, it is necessary to perform an in-depth analysis of acidfree acrylic OCAs and their potential compatibility with stepwise curing. Two types of OCA prepolymers were employed for our curing experiments: one that contains AA and another that does not. In this study, it was shown that after the polymerization of solvent-free UV-curable OCA syrups in the presence of methyl methacrylate as a polymerization inhibitor, UV/UV-stepwise curing of OCAs both with and without AA is possible.

\section{Experimental}

\subsection{Materials}

Two types of OCA were synthesized in this study: OCA-1, a standard PSA that contains an acrylic acid, and OCA-2, a PSA without acrylic acid. Acrylic monomers, 2-ethylhexyl acrylate (2-EHA, 99.0\% purity) and acrylic acid (AA, 99.0\% purity) were purchased from Samchun Pure Chemical. Isobornyl acrylate (IBA, 99\% purity) was purchased from Sigma Aldrich. Methyl methacrylate (MMA, 99.0\% purity, Samchun Pure Chemical) was used to reduce the reactivity and 2-hydroxyethyl acrylate (2-HEA, 99\% purity, Samchun Pure Chemical) was used to improve cohesion. All chemicals were used without further purification. The specific ratios of the compounds used in the synthesis of pre-polymers are listed in Table 1.

Table 1. Compositions of the raw materials used for the synthesis of pre-polymers.

\begin{tabular}{|l|l|c|c|}
\hline \multicolumn{2}{|c|}{ Sample name } & OCA-1 & OCA-2 \\
\hline \multirow{4}{*}{$\begin{array}{l}\text { Monomer } \\
\text { composition [\%] }\end{array}$} & 2-ethylhexyl acrylate & 64 & 62 \\
\cline { 2 - 4 } & Isobornyl acrylate & 19 & 19 \\
\cline { 2 - 4 } & Acrylic acid & 3 & 0 \\
\cline { 2 - 4 } & Methyl methacrylate & 4 & 4 \\
\cline { 2 - 4 } & 2-hydroxyethyl acrylate & 10 & 15 \\
\hline Photo initiator [\%] & $\begin{array}{l}\text { Hydroxydimethyl } \\
\text { acetophenone }\end{array}$ & 0.3 & 0.3 \\
\hline
\end{tabular}




\subsection{Synthesis of the pre-polymer}

The pre-polymer was synthesized from 2-ethylhexyl acrylate, acrylic acid, isobornyl acrylate, methyl methacrylate, and 2-hydroxyethyl acrylate via bulk radical polymerization [24]. Mixtures of monomers were initiated with $0.3 \mathrm{wt} \%$ hydroxydimethyl acetophenone( $98 \%$ purity, Shinyoung Rad. Chem.). Polymerization was performed in a $500 \mathrm{ml}$ four-necked flask, with a mechanical stirrer, $\mathrm{N}_{2}$ inlet, thermometer, and a light-emitting diode (LED) UV lamp. The temperature was maintained at room temperature $\left(23^{\circ} \mathrm{C}\right)$ with constant stirring at $100 \mathrm{rpm}$. After $\mathrm{N}_{2}$ purging for 30 min under constant stirring, the monomer mixtures were subsequently exposed to a UV lamp $\left(20 \mathrm{~mW} / \mathrm{cm}^{2}\right)$, while increasing the temperature by $15^{\circ} \mathrm{C}$ and performing $\mathrm{N}_{2}$ purging. The chemical reaction is shown in Figure 1. First, the $\mathrm{C}=\mathrm{C}$ double bond of the acrylate group of the monomer is broken by the radicals generated via light-induced cleavage of hydroxydimethyl acetophenone [25]. Acrylic groups containing radicals break through the double bonds in the acrylic groups of other neighboring monomers, and a continuous chain polymerization reaction proceeds [26]. Because of steric effects and stability of the radical, methacrylates slowly participate in the polymerization reaction [27]. The added monomers are randomly arranged in the prepolymer. AA and MMA also participate in the reaction, but their proportion in the prepolymer is small because of the small addition amount. There is no

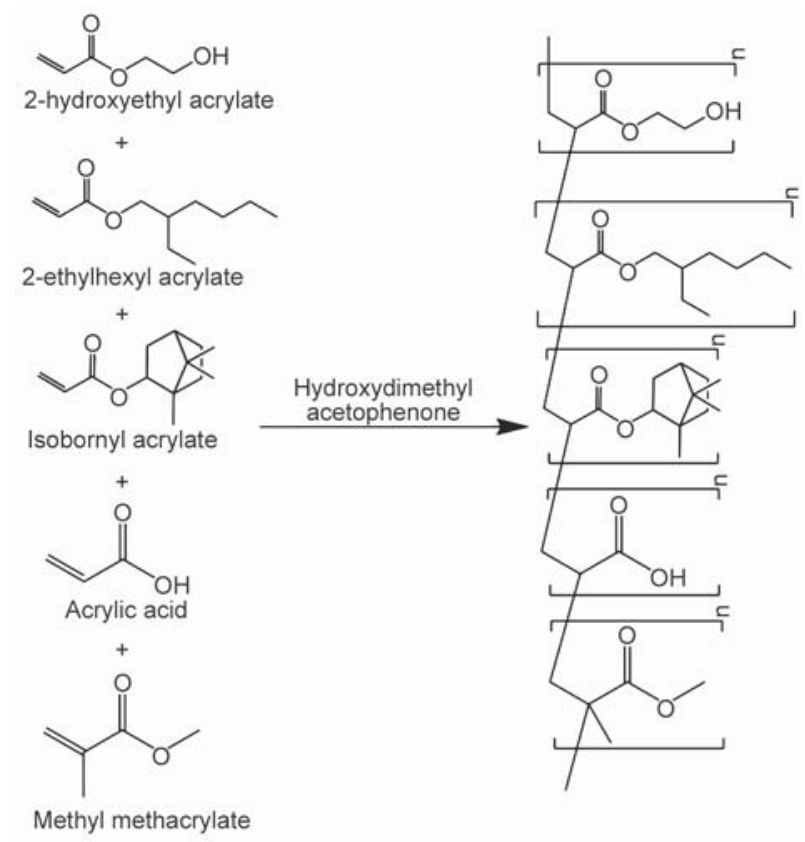

Figure 1. Synthesis of the OCA prepolymer.
AA monomer unit in the chemical structure of the OCA-2 prepolymer.

\subsection{Preparation of UV-curable OCA syrup}

UV-curable syrups were prepared by blending the pre-polymer with ethoxylated (3) trimethylolpropane triacrylate (EO3TMPTA, Sigma-Aldrich) and ethoxylated (9) trimethylolpropane triacrylate (EO9TMPTA, Sigma-Aldrich), at a ratio of 7:3. These are multifunctional acrylates that are commonly employed to evaluate blended binary systems.

A mixture of EO3TMPTA and EO9TMPTA was selected to decrease the UV curing rate during primary curing. This left unreacted monomers after primary curing, which were consumed during secondary curing. Hydroxydimethyl acetophenone (Micure HP-8, Miwon Specialty Chemical, Republic of Korea) was used as the photo-initiator. The absorption ranges of $\mathrm{nm}$ and $320-335 \mathrm{~nm}$.

\subsection{Preparation of cured acrylic OCA: Step curing}

OCA syrup was coated on corona-treated polyethylene terephthalate films (PET, SKC Co. Ltd., Republic of Korea) at a thickness of $100 \mu \mathrm{m}$. In the primary curing steps, the coated resin was cured by passing under a black light UV-curing machine equipped with a low-pressure mercury UV lamp $\left(20 \mathrm{~mW} / \mathrm{cm}^{2}\right.$, main wavelength $365 \mathrm{~nm}$ ) for different durations. Light irradiance is inversely proportional to the distance of the UV lamp distance from the curing materials, which also changes the curing speed and behavior [28]. The UV lamp was placed $3 \mathrm{~cm}$ away from the curing materials for primary curing. The UV irradiation dose for primary curing was $0.3 \mathrm{~J} / \mathrm{cm}^{2}$ per $1 \mathrm{~min}$. OCA samples were cured for 2 , 3,4 , and $5 \mathrm{~min}$ in the case of primary curing. Name$1 \mathrm{y}$, the samples were cured at $0.6,0.9,1.2$, and $1.5 \mathrm{~J} / \mathrm{cm}^{2}$, respectively, in the primary curing stage. In primary curing, covalent bonds were formed by suitable functional groups located on the triacrylate binder molecule. Eventually, some polymer chains were crosslinked [29].

In the secondary curing steps, the primary-cured film was cured by passing under a conveyor-type metal halide UV-curing machine equipped with mediumpressure mercury UV lamps $\left(154 \mathrm{~mW} / \mathrm{cm}^{2}\right.$, main wavelength $=365 \mathrm{~nm}$ ). The UV lamp was placed $15 \mathrm{~cm}$ away from the curing materials during secondary curing. The UV irradiation dose for secondary 


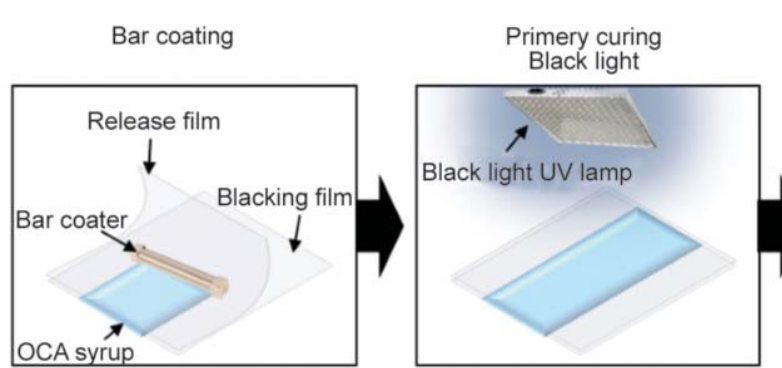

Figure 2. UV/UV stepwise curing process for the OCA.

curing was fixed at $3 \mathrm{~J} / \mathrm{cm}^{2}$. In secondary curing, the remaining triacrylate molecules in the binder reacted with the acrylate polymer to form a crosslinked three-dimensional network. The curing process is illustrated in Figure 2.

\subsection{Photo-differential scanning calorimetry (Photo-DSC)}

The UV-curing behavior of adhesives was evaluated using a differential scanning calorimeter (DSC; DSC Q200, TA Instruments, USA) equipped with a photocalorimetric accessory. The light source was spotcure (Omnicure-s2000, Excelitas, Waltham, MA, USA), using a $100 \mathrm{~W}$ mercury-vapor lamp. The amount of light energy was determined by placing an empty open aluminum DSC pan on the sample cell. The UV light level of the UV accessory with a $90 \%$ UV filter was 10 . The sample weight was approximately $13-15 \mathrm{mg}$. All measurements were carried out at a temperature of $25^{\circ} \mathrm{C}$.

\subsection{Adhesion properties}

\subsubsection{Peel strength}

The bonded specimens were prepared as $25 \mathrm{~mm}$ wide samples. The $180^{\circ}$ peel strength was carried out using a Texture Analyzer (TA-XT2i, Micro Stable Systems, UK). The specimens were left to stand at room temperature for $24 \mathrm{~h}$. A peeling test crosshead speed of $300 \mathrm{~mm} / \mathrm{min}$ was employed at a temperature of $20^{\circ} \mathrm{C}$, based on ASTM D3330. The force was recorded in $\mathrm{N}$ units for three different runs, and the average force was recorded as N/25 mm.

\subsubsection{Probe tack}

The probe tack was measured using a Texture Analyzer (TA-XT2i, Micro Stable Systems, UK) with a $5 \mathrm{~mm}$ diameter stainless steel cylinder probe at $20^{\circ} \mathrm{C}$. In the first step, the approaching speed of the probe was $0.5 \mathrm{~mm} / \mathrm{s}$. In the second step, the probe was in contact with the surface of the OCAs for $1 \mathrm{~s}$ at a constant pressure of $100 \mathrm{~g} / \mathrm{cm}^{2}$ and the debonding

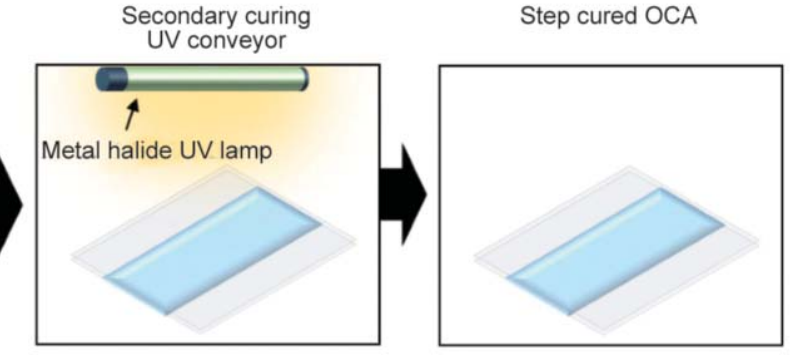

speed was $0.5 \mathrm{~mm} / \mathrm{s}$. The probe tack was used as a measure of the maximum debonding force (ASTM D3330).

\subsection{Viscoelastic properties (DMA)}

The temperature-dependence of the dynamic storage modulus $\left(E^{\prime}\right)$ and the $\tan \delta$ values of the adhesives were evaluated using a dynamic mechanical analyzer (DMA Q800, TA instruments, USA) in the film-tension mode. Specimens of approximately $11-13 \mathrm{~mm}$ length, $12 \mathrm{~mm}$ width, and $3 \mathrm{~mm}$ thickness were prepared. The test was conducted at a strain rate of $0.1 \%$ and frequency of $1 \mathrm{~Hz}$, with a heating rate of $5 \mathrm{~K} / \mathrm{min}$ within the temperature range of 213.15 $373.15 \mathrm{~K}$.

\subsection{Gel fraction}

The gel fraction test is a convenient method for measuring the quantity of insoluble components, such as the fractions of crosslinked or network polymers. Gel fraction depends on the solubility parameter of the solvent. In this study, toluene was selected as the solvent. The gel content is a significant factor in terms of curing behavior. The gel fractions of the cross-linked adhesives were determined by soaking them in toluene at $60^{\circ} \mathrm{C}$ for $24 \mathrm{~h}$. The insoluble part was removed by filtration and dried at $60^{\circ} \mathrm{C}$ to a constant weight. The gel fraction was calculated using Equation (1):

Gel fraction $[\%]=\frac{w_{1}}{w_{0}} \cdot 100$

where $w_{0}$ and $w_{1}$ are the weights of adhesive before and after filtration, respectively.

\subsection{UV-visible spectroscopy}

The transmittance of the UV-cured acrylic OCAs was examined by UV-visible spectroscopy (UV2550, Shimadzu, Japan). The transmittance of two release films was measured and used for the control data. The transmittance of the OCA samples was 
measured with a release film on both sides. The transmittance was determined to be in the visible range of 400-800 $\mathrm{nm}$. The thicknesses of all acrylic OCA films deposited between the transparent release films were $60 \mu \mathrm{m}$.

\section{Results and discussion}

\subsection{Photo-differential scanning calorimetry (photo-DSC)}

The reaction rate can be measured by monitoring the rate at which heat is released from a polymerizing sample, because polymerization is generally an exothermic reaction. Therefore, the profiles of the heat of reaction versus time, obtained by photo-DSC, can be used to characterize reaction kinetics and evaluate polymerization rate constants [30]. The crosslinking sites that remain after primary curing cause an exothermic reaction when exposed to UV during secondary curing. Figure $3 \mathrm{a}$ and $3 \mathrm{c}$ indicate the heat flow for OCA-1 and OCA-2 samples irradiated with UV light after primary curing, respectively. Many reaction sites remained in the samples that were cured with $0.6 \mathrm{~J} / \mathrm{cm}^{2} \mathrm{UV}$ light, resulting in a large amount
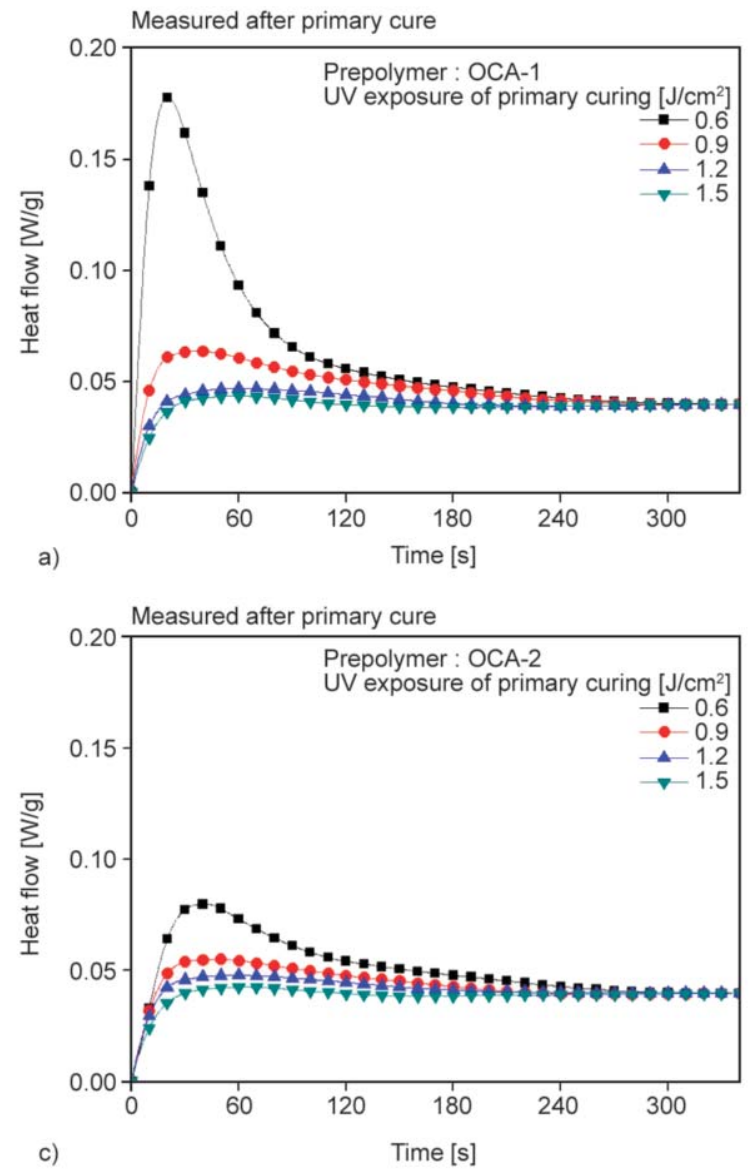

of additional reaction and heat generation. The samples that were cured at $0.9 \mathrm{~J} / \mathrm{cm}^{2}$ exhibit a low exothermic peak compared to that at $0.6 \mathrm{~J} / \mathrm{cm}^{2} 2$, while the samples that were cured at 1.2 and $1.5 \mathrm{~J} / \mathrm{cm}^{2}$ show almost no peak. Figure $3 \mathrm{~b}$ and $3 \mathrm{~d}$ indicates the remaining reaction sites and additional reactions of the OCA-1 and OCA-2 samples after secondary curing. Very small peaks are observed only at $0.6 \mathrm{~J} / \mathrm{cm}^{2}$ UV light exposure for the OCA-1 and OCA-2 samples, while almost no exothermic peaks are observed in other samples after the second curing reaction. This implies that, with the exception of the samples that were exposed to $0.6 \mathrm{~J} / \mathrm{cm}^{2} \mathrm{UV}$ light energy amount, almost all the reaction sites reacted during secondary curing, and no additional crosslinking reactions occurred.

Figure 4 shows the integral of photo-DSC data. This data represents the total amount of UV-induced reaction during photo-DSC measurement, which is equivalent to the quantity of residual reaction sites after primary/secondary curing. The primary-cured samples showed more additional reactions in both the OCA-1 and OCA-2 samples at an illumination
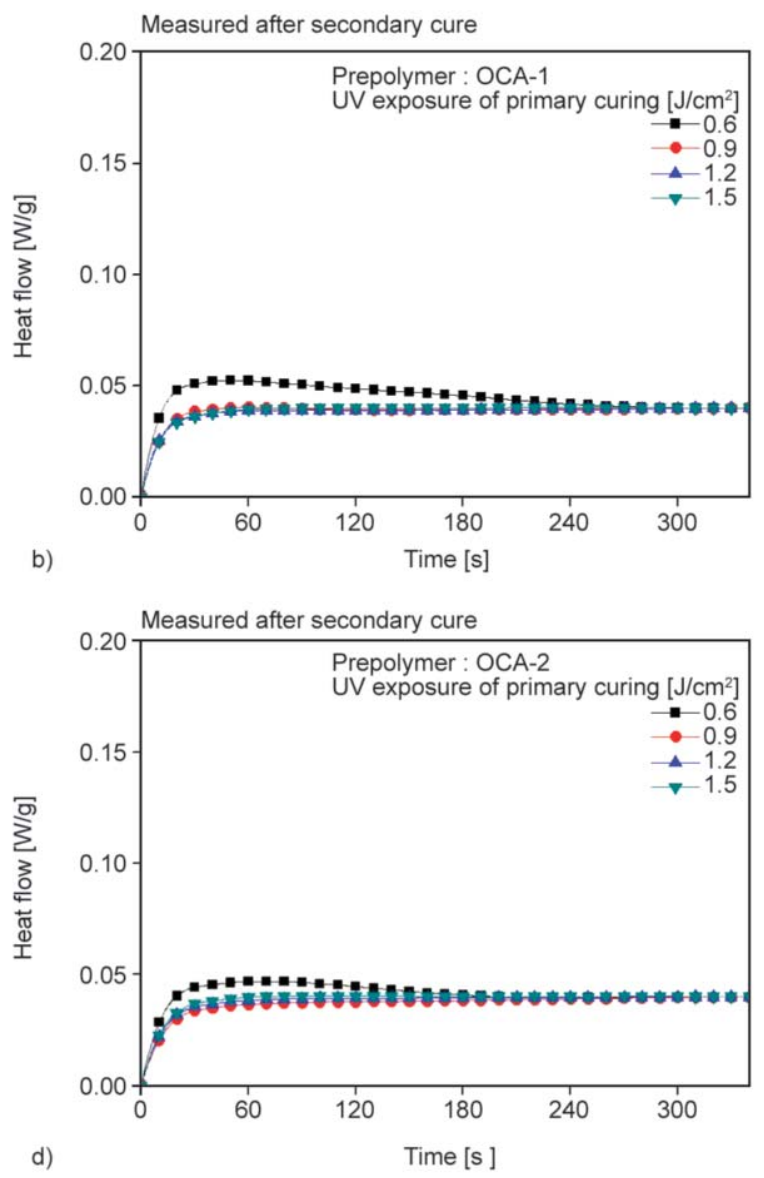

Figure 3. Real-time heat flow after (a) primary and (b) secondary curing steps for OCA-1, and after (c) primary and (d) secondary curing steps for OCA-2. 

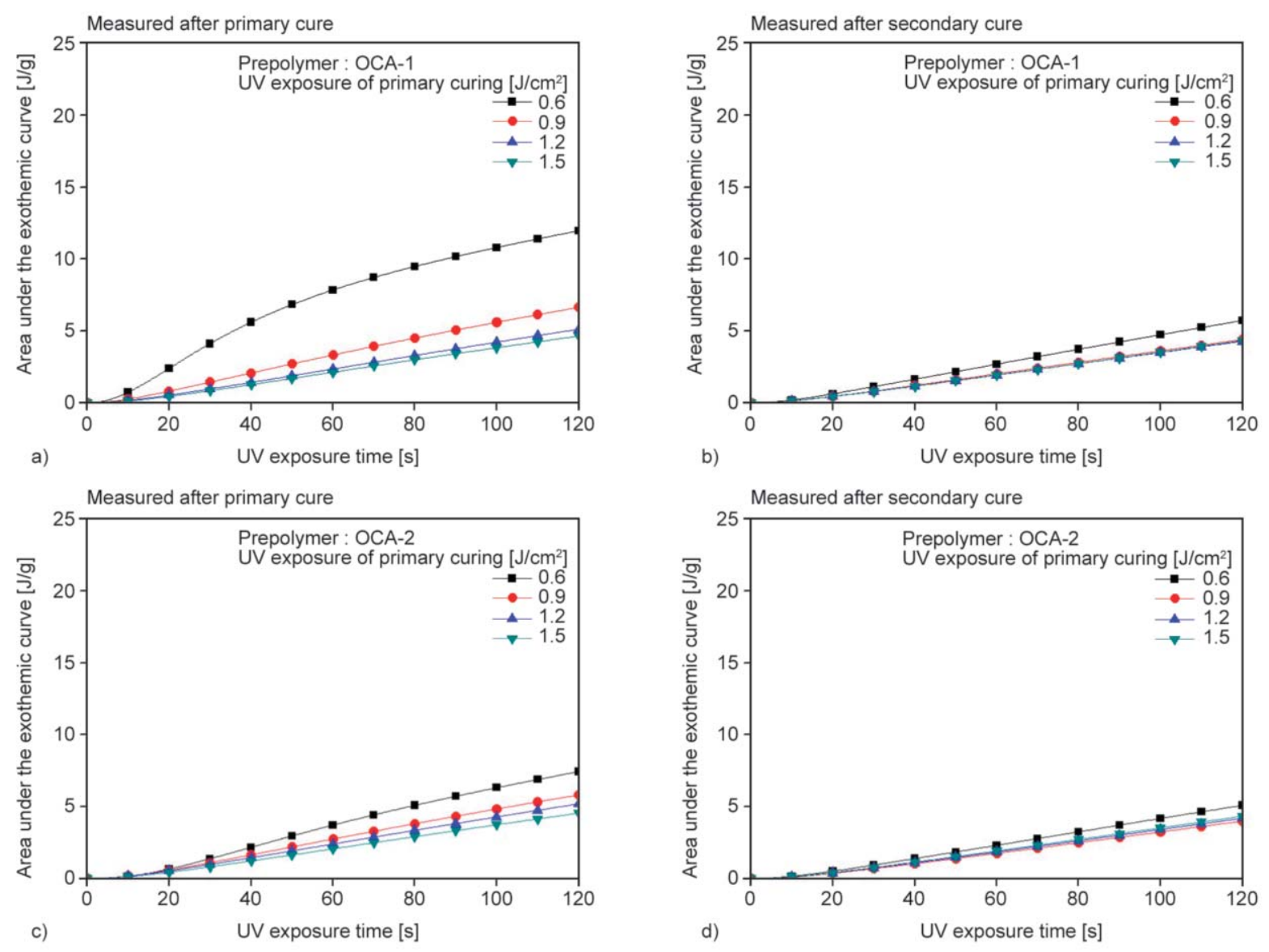

Figure 4. Area under the exothermic curves corresponding to (a) primary and (b) secondary curing steps of OCA-1, and (c) primary and (d) secondary curing steps of OCA-2.

energy amount of $0.6 \mathrm{~J} / \mathrm{cm}^{2}$ after primary curing, and the amount of reaction decreased upon increasing the energy amounts to $0.9,1.2$, and $1.5 \mathrm{~J} / \mathrm{cm}^{2}$. After secondary curing, the samples showed a slight reaction at an illumination energy amount of $0.6 \mathrm{~J} / \mathrm{cm}^{2}$. Samples illuminated at $0.9,1.2$, and $1.5 \mathrm{~J} / \mathrm{cm}^{2}$ rarely reacted, which implies that these samples were completely cured after the secondary curing step.

Figure 5 shows the maximum heat flows and the corresponding approach times for both primary and secondary curing. This data is crucial for describing the primary curing of the samples. As shown in Figure 5a and $5 \mathrm{c}$, in case of primary curing, the heat flow values of the peaks decrease with increasing UV light exposure time. The corresponding approach times tend to increase as the amount of UV energy used in primary curing increases. This implies that during photoDSC, the reaction rate will be faster, and the extent of reaction will be greater as the number of residual sites increases after primary curing. The data for samples after secondary curing, shown in Figure $5 \mathrm{~b}$ and $5 \mathrm{~d}$, is not particularly meaningful, since there are no peaks in Figure $4 \mathrm{~b}$ and $4 \mathrm{~d}$.

\subsection{Adhesion property}

\subsubsection{Peel strength}

Crosslinking density is an important parameter for controlling the adhesion performance of a material [31]. Figure 6 shows the peel strengths of OCA-1 and OCA-2 samples after primary and secondary curing. The peel strength of all samples tended to increase after secondary curing, especially the OCA-2 samples, which showed a large increase. Both the OCA-1 and OCA-2 primary-cured samples showed an increase in peel strength with increasing UV light exposure time, except for the sample exposed to $1.5 \mathrm{~J} / \mathrm{cm}^{2} \mathrm{UV}$ light. This may be attributed to the formation of a polymer network with high crosslinking density with increased light exposure. The drop in the fill value for $1.5 \mathrm{~J} / \mathrm{cm}^{2} \mathrm{UV}$-exposed samples implies that the fast crosslinking reaction triggered by primary curing had an adverse effect on adhesion. However, since after secondary curing, the samples exhibit stable peel strength of $30 \mathrm{~N} / 25 \mathrm{~mm}$, the crosslinking structure formed through secondary curing may differ from that formed through primary curing. 

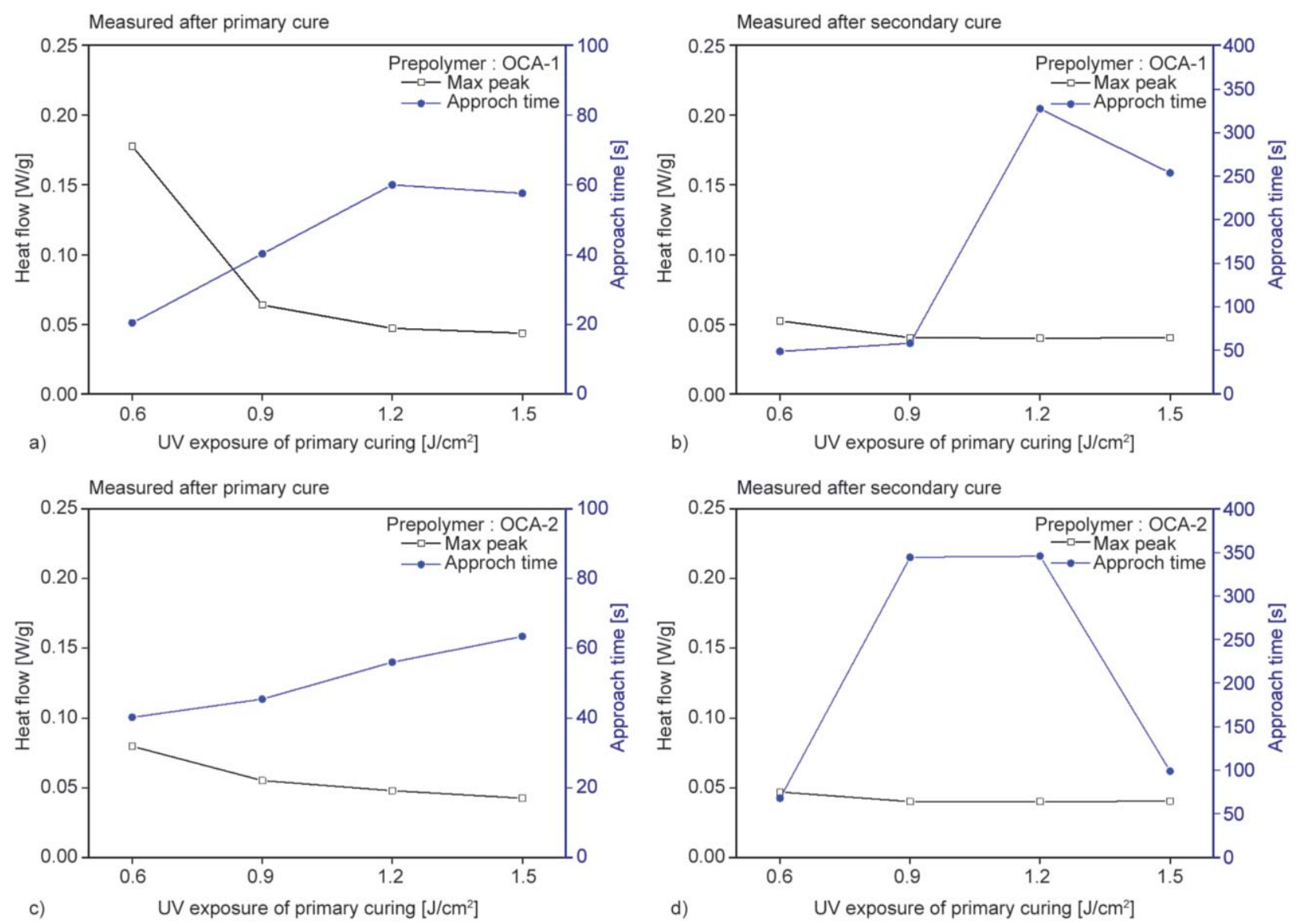

Figure 5. Maximum heat flows and corresponding approach times for (a) primary and (b) secondary curing steps of OCA-1, and (c) primary and (d) secondary curing steps of OCA-2.

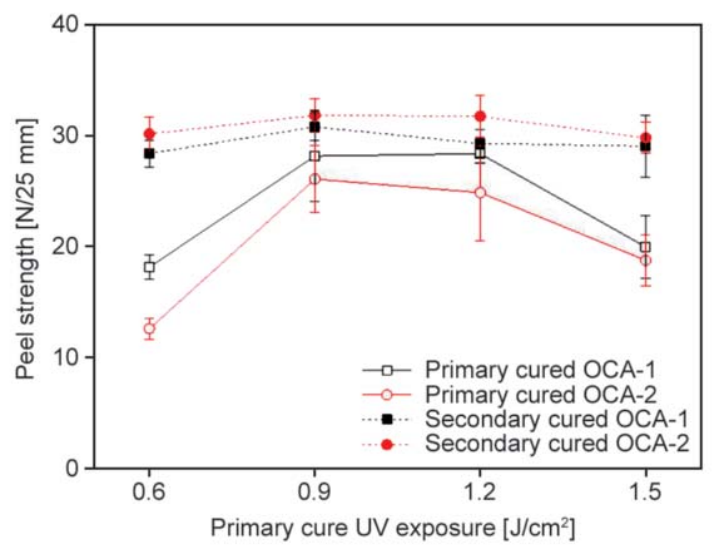

Figure 6. Peel strength as a function of UV light energy amount.

\subsubsection{Probe tack}

Figure 7 shows the probe tack values of all samples. The probe tack values increased significantly after secondary curing when the UV light energy amount for primary curing is $0.6 \mathrm{~J} / \mathrm{cm}^{2}$. For UV light exposure $\geq 0.9 \mathrm{~J} / \mathrm{cm}^{2}$, the differences in probe tack values between the primary-cured and secondary-cured samples are not significant. This result indicates that the different crosslinking structures induced by primary

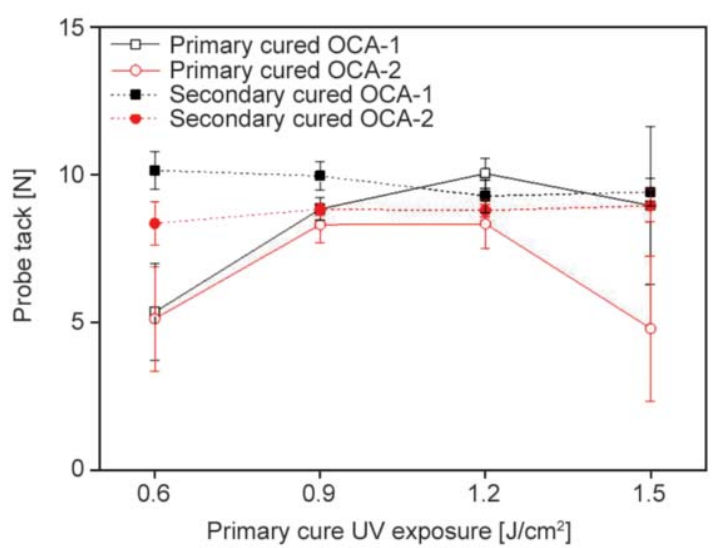

Figure 7. Probe tack as function of UV light energy amount.

and secondary curing do not have a great influence on tack values.

\subsection{Viscoelastic properties (DMA)}

The viscoelastic properties of PSAs are associated with their adhesion performance and curing behaviors [4]. The storage modulus represents the elastic deformation of PSAs and their hardness at a given temperature and frequency [32]. Figure $8 \mathrm{a}$ and $8 \mathrm{c}$ represent the temperature-dependent storage modulus 

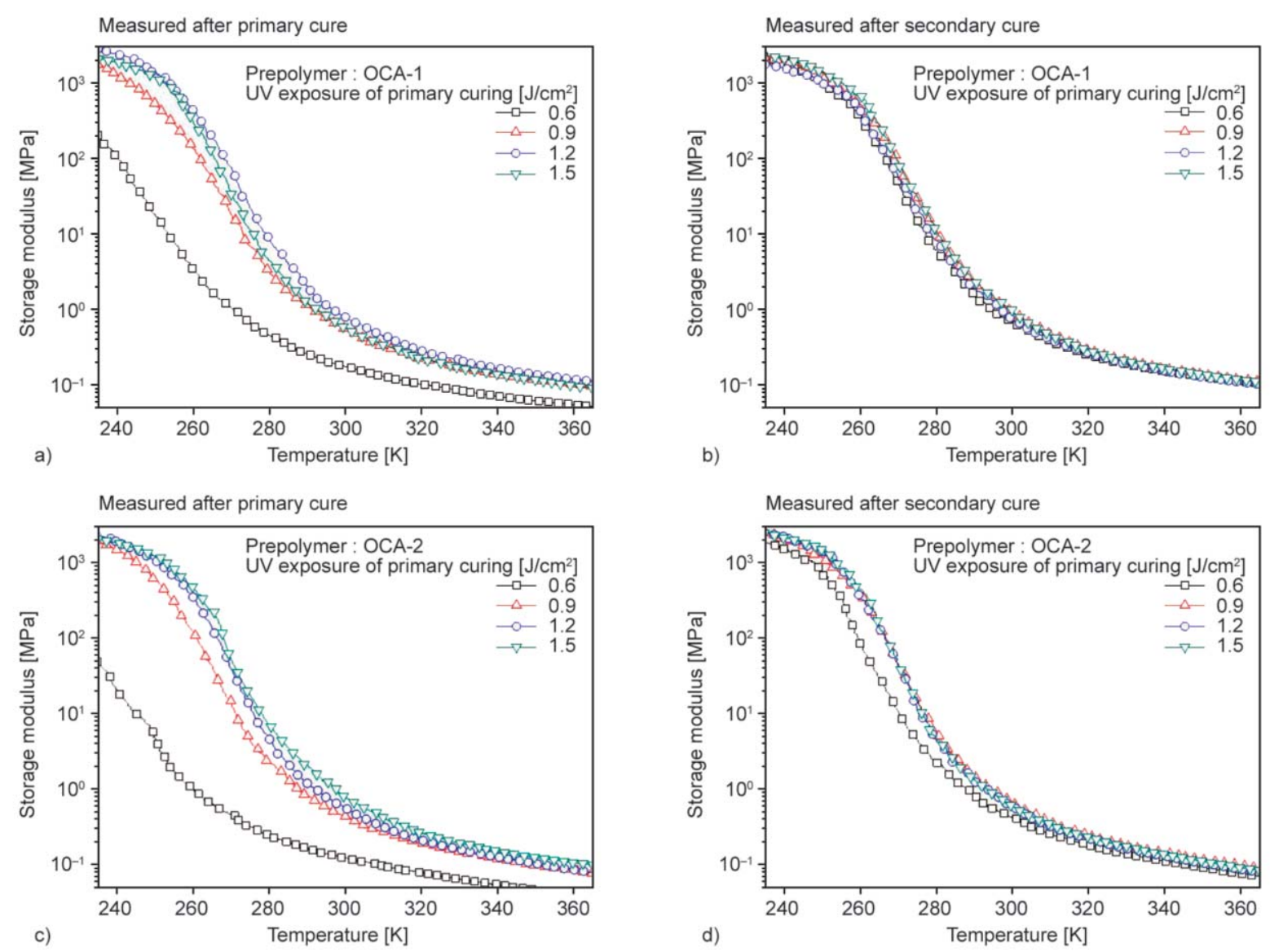

Figure 8. Temperature-dependence of the PSA storage modulus determined for different amounts of UV energy. Results are shown for (a) primary and (b) secondary-cured OCA-1 samples, and (c) primary and (d) secondary-cured OCA-2 samples.

of cured acrylic OCA-1 and OCA-2, respectively, after primary curing. This figure indicates a soft OCA characteristic due to low curing density after primary curing, thus leading to a low storage modulus. The storage modulus is the lowest for $0.6 \mathrm{~J} / \mathrm{cm}^{2} \mathrm{UV}$ light exposure and the hardness of the cured OCA increases with increasing UV light exposure time, thus the storage modulus tends to increase. The storage modulus increased after secondary curing, as shown in Figure $8 \mathrm{~b}$ and $8 \mathrm{~d}$.

Figure 9 shows the effect of temperature on the $\tan \delta$ of crosslinked acrylic PSAs after primary and secondary curing. The temperature at the maximum $\tan \delta$ is known to correspond to the glass transition temperature $\left(T_{\mathrm{g}}\right)$ [33]. The primary-cured samples showed a $\tan \delta$ peak at the lowest temperature for $0.6 \mathrm{~J} / \mathrm{cm}^{2}$ UV light exposure, and a peak near $0{ }^{\circ} \mathrm{C}$ for $0.9 \mathrm{~J} / \mathrm{cm}^{2}$ UV light exposure. The samples exposed to 1.2 and $1.5 \mathrm{~J} / \mathrm{cm}^{2} \mathrm{UV}$ light showed peaks at similar temperatures. The OCA-1 samples exhibited peaks at similar temperatures after secondary curing, whereas OCA-2 samples exposed to $0.6 \mathrm{~J} / \mathrm{cm}^{2} \mathrm{UV}$ light only showed a lower $T_{\mathrm{g}}$ than other samples after secondary curing.

\subsection{Gel-fraction test}

The synthesized PSA pre-polymers contain acrylate groups in their backbone, which undergo crosslinking reactions when the material is irradiated by UV. The crosslinking density of the obtained PSA samples can be determined indirectly by calculating their corresponding gel contents from the polymer insoluble fractions [31]. Increased gel content implies higher crosslinking reactions [34]. Here, the PSA gel content was calculated after primary irradiation at various UV doses, and after secondary UV doses. The changes in the gel content after primary and secondary UV irradiations are shown in Figure 10. After primary UV irradiation, the gel contents tended to increase with increasing UV exposure. OCA-1 samples exposed to $0.9,1.2$, and $1.5 \mathrm{~J} / \mathrm{cm}^{2} \mathrm{UV}$ light exhibit a stable gel fraction of more than $90 \%$. This is because, the polymerization of the methacrylate monomer in the resin composite induces a highly crosslinked structure 

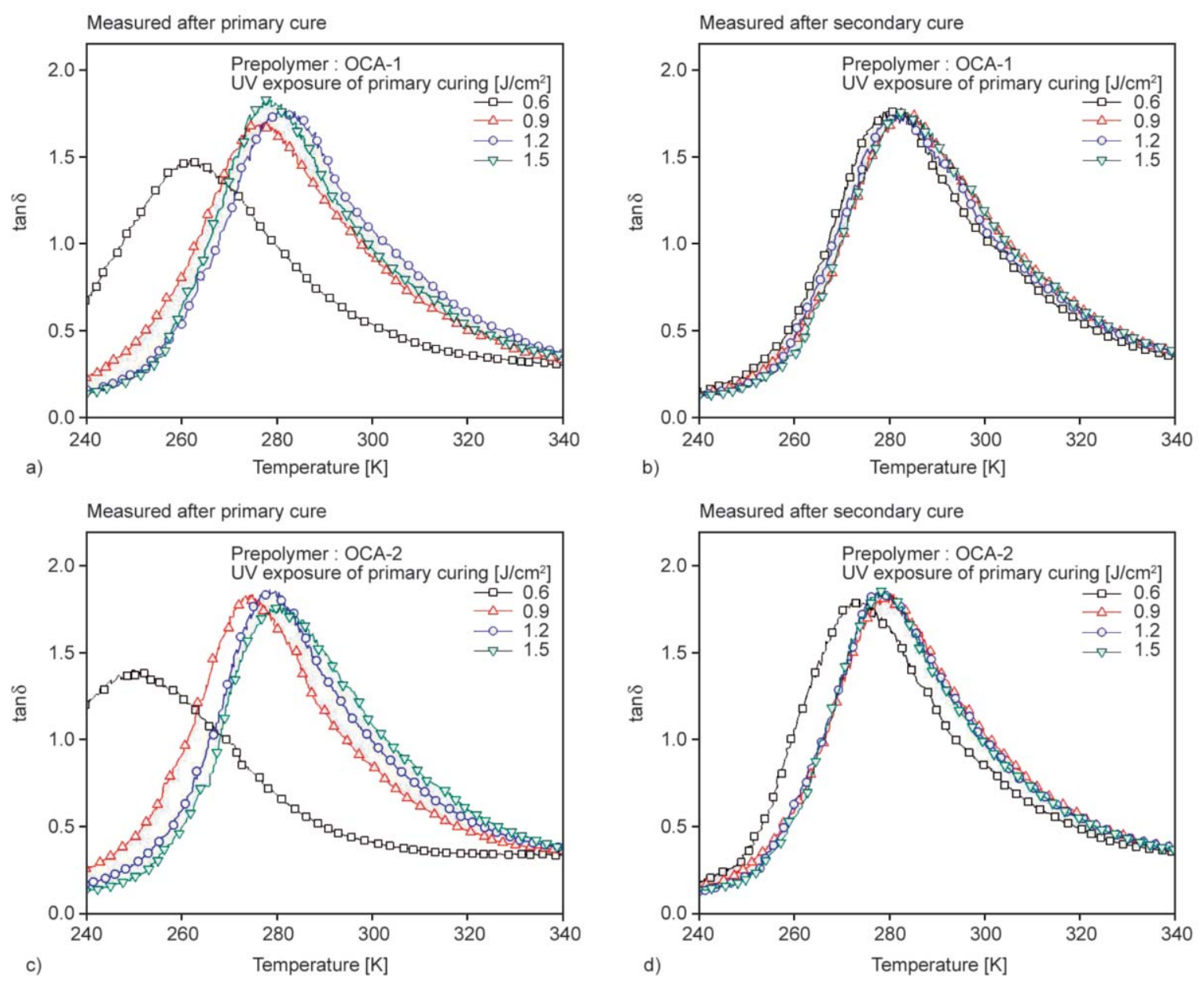

Figure 9. Temperature-dependent $\tan \delta$ of crosslinked acrylic PSAs prepared with different amounts of UV energy: (a) primary and (b) secondary-cured OCA-1, (c) primary and (d) secondary-cured OCA-2.

[35]. OCA-2 samples, which are synthesized without AA, show a gel fraction as low as $80 \%$ when compared to that of OCA-1 samples irradiated with UV light for the same duration. This result implies that the absence of AA has a negative effect on the

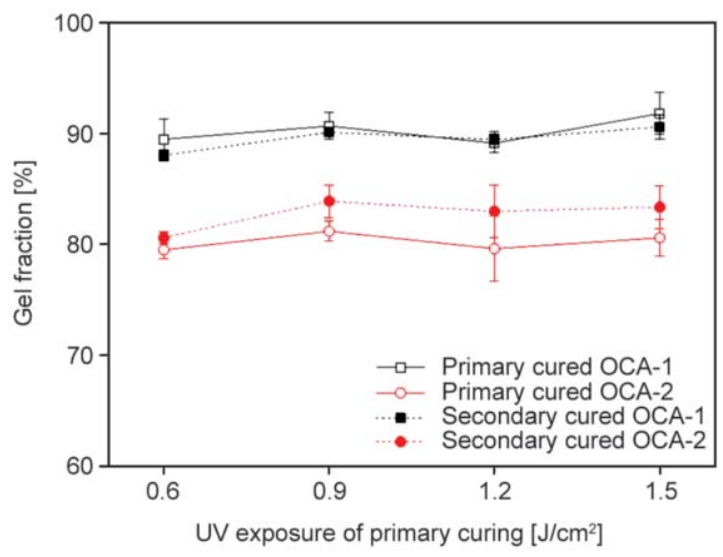

Figure 10. Gel fractions of crosslinked acrylic OCAs prepared using various amounts of UV energy. crosslinking reaction, which is consistent with the low adhesive properties observed after primary curing of OCA-2. OCA-1 samples show little change in gel fraction after secondary curing, whereas OCA-1 samples show a relatively large increase, from 80 to $84 \%$, after secondary curing.

\subsection{UV-visible spectroscopy}

The transmittance of the OCAs is an important parameter, because it is directly related to the possibility of its use in display applications. In this study, 'optically clear' infers that more than $95 \%$ of visible light can transmit through the adhesive, as shown in Figure 11. Two release films not containing OCA were used for baseline correction, which was equal to $100 \%$. The measured transmittances of the acrylic PSAs are above $100 \%$, indicating that the acrylic PSA-coated PET films exhibit better transparency than that of the neat films support [19]. 

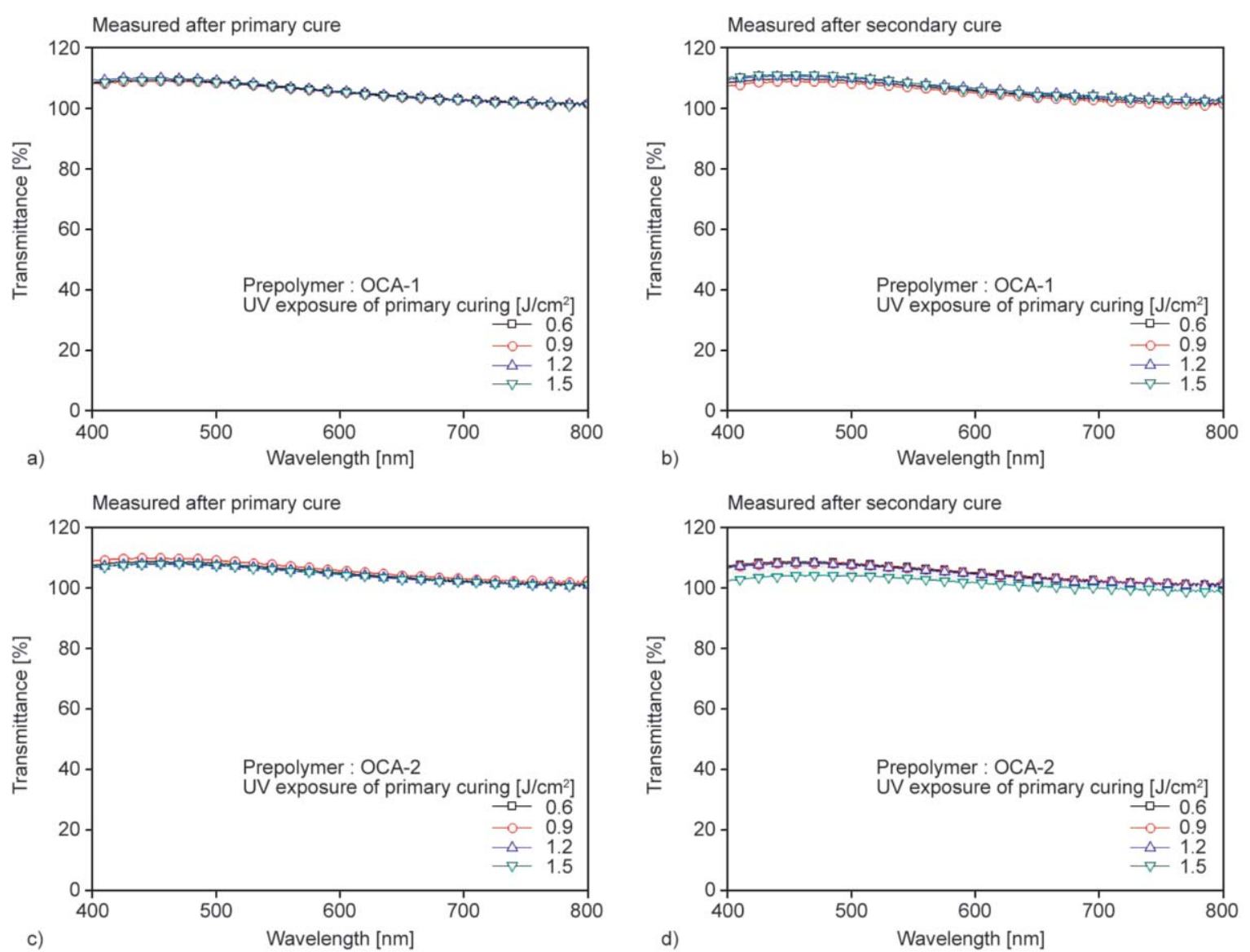

Figure 11. Transmittance of crosslinked acrylic OCAs prepared using various amounts of UV energy: (a) primary and (b) secondary-cured OCA-1, (c) primary and (d) secondary-cured OCA-2.

\section{Conclusions}

The sequential curing behavior OCA samples with and without acrylic acid was investigated with different UV irradiation times of primary curing. The exhaustion of all reaction sites after secondary curing was also observed. Samples exposed to $0.6 \mathrm{~J} / \mathrm{cm}^{2}$ UV light for primary curing were not fully cured even after secondary curing. It was confirmed that some reaction sites remained. In case of samples cured using $0.6,1.2$, and $1.5 \mathrm{~J} / \mathrm{cm}^{2} \mathrm{UV}$ light energy, which were fully cured after secondary curing, uniformly improved adhesion properties, storage modulus, and $T_{\mathrm{g}}$ were observed, regardless of the duration of primary curing. These results confirm that UV/UV stepwise curing is possible for both acid/ non-acid OCA, and the appropriate primary curing conditions for step curing is found to be UV energy amount over $0.9 \mathrm{~J} / \mathrm{cm}^{2}$. This study presents an approach that provides enhanced processability of OCAs for use in mobile display manufacturing. Further research will focus on introducing the possibil- ity of step curing identified in this study to the actual industrial manufacturing process for smart devices. Based on the possibilities of step curing confirmed in this study, further research and optimization of the adhesion performance of primary and secondarycured OCAs suitable for industrial processes will be conducted.

\section{Acknowledgements}

This work was supported by LMS Co., Ltd. (Republic of Korea).

\section{References}

[1] Park C. H.: Characterization and aging behavior of optically clear acrylic adhesives for touch screen panel. $\mathrm{PhD}$ thesis, Seoul National University (2015).

[2] Kuo C-F. J., Chen J-B., Chang S-H.: Low corrosion optically clear adhesives for conducting glass: I. Effects of $\mathrm{N}, \mathrm{N}$-diethylacrylamide and acrylic acid mixtures on optically clear adhesives. Journal of Applied Polymer Science, 135, 46277/1-46277/7 (2018). https://doi.org/10.1002/app.46277 
[3] Chang E. P., Holguin D.: Curable optically clear pressure-sensitive adhesives. Journal of Adhesion, 81, 495508 (2005).

https://doi.org/10.1080/00218460590944945

[4] Lee S-W., Park J-W., Park C-H., Kwon Y-E., Kim H-J., Kim E-A., Woo H-S., Schwartz S., Rafailovich M., Sokolov J.: Optical properties and UV-curing behaviors of optically clear $\mathrm{PSA}_{-} \mathrm{TiO}_{2}$ nano-composites. International Journal of Adhesion and Adhesives, 44, 200-208 (2013).

https://doi.org/10.1016/j.ijadhadh.2013.03.001

[5] Lee S-W., Park J-W., Park C-H., Kim H-J.: Enhanced optical properties and thermal stability of optically clear adhesives. International Journal of Adhesion and Adhesives, 50, 93-95 (2014).

https://doi.org/10.1016/j.ijadhadh.2013.12.029

[6] Kim S., Lee S-W., Lim D-H., Park J-W., Park C-H., Kim H-J.: Optical properties and adhesion performance of acrylic PSAs; Influence of functionalized monomer and curing agent. Journal of Adhesion Science and Technology, 27, 2265-2277 (2013).

https://doi.org/10.1080/01694243.2013.763481

[7] Pokeržnik N., Krajnc M.: Synthesis of a glucose-based surfmer and its copolymerization with $n$-butyl acrylate for emulsion pressure sensitive adhesives. European Polymer Journal, 68, 558-572 (2015).

https://doi.org/10.1016/j.eurpolymj.2015.03.038

[8] Fang C., Wang Y., Lin Z., Daniels E. S., Klein A.: Partitioning of monobutyl itaconate and $\beta$-carboxyethyl acrylate between organic and water phases. Journal of Applied Polymer Science, 131, 40868/1-46868/7 (2014). https://doi.org/10.1002/app.40868

[9] Czech Z., Pełech R.: The thermal degradation of acrylic pressure-sensitive adhesives based on butyl acrylate and acrylic acid. Progress in Organic Coatings, 65, 84 87 (2009).

https://doi.org/10.1016/j.porgcoat.2008.09.017

[10] Micutz M., Aricov L., Ilie C., Staicu T.: Tailoring rheological properties of uncrosslinked water-borne pressure-sensitive adhesives by means of polymer maximum volume fraction. International Journal of Adhesion and Adhesives, 70, 10-16 (2016).

https://doi.org/10.1016/j.ijadhadh.2016.05.001

[11] Hösel M., Søndergaard R. R., Jørgensen M., Krebs F. C.: Comparison of UV-curing, hotmelt, and pressure sensitive adhesive as roll-to-roll encapsulation methods for polymer solar cells. Advanced Engineering Materials, 15, 1068-1075 (2013). https://doi.org/10.1002/adem.201300172

[12] Czech Z., Kowalczyk A., Kabatc J., Świderska J.: UVcrosslinkable acrylic pressure-sensitive adhesives for industrial application. Polymer Bulletin, 69, 71-80 (2012).

https://doi.org/10.1007/s00289-012-0725-y
[13] Grabowska B., Holtzer M.: Structural examination of the cross-linking reaction mechanism of polyacrylate binding agents. Archives of Metallurgy and Materials, 54, 427-437 (2009).

[14] Czech Z., Kowalczyk A., Gąsiorowska M., Soroka J., Kabatc J.: Novel pyridinium derivatives as very efficient photoinitiators for UV-activated synthesis of acrylic pressure-sensitive adhesives. International Journal of Adhesion and Adhesives, 31, 634-638 (2011). https://doi.org/10.1016/j.ijadhadh.2011.06.004

[15] Kajtna J., Krajnc M.: 'Design of experiments' analysis in study of solventless UV crosslinkable acrylic pressure sensitive adhesives. International Journal of Adhesion and Adhesives, 41, 152-159 (2013).

https://doi.org/10.1016/j.ijadhadh.2012.11.005

[16] Noori H., Jain M., Nielsen K., Brandys F.: Delamination in deformed polymer laminated sheet metals. International Journal of Adhesion and Adhesives, 85, 219224 (2018).

https://doi.org/10.1016/j.ijadhadh.2018.06.014

[17] Kim Y-B., Park S-C., Kim H-K., Hong J-W.: Dual-curable acrylic pressure-sensitive adhesives based on UV and thermal processes. Macromolecular Research, 16, 128-133 (2008).

https://doi.org/10.1007/BF03218841

[18] Lee S-W., Park J-W., Park C-H., Kim H-J., Kim E-A., Woo H-S.: Optical properties and adhesion performance of optically clear acrylic pressure sensitive adhesives using chelate metal acetylacetonate. International Journal of Adhesion and Adhesives, 47, 21-25 (2013). https://doi.org/10.1016/j.ijadhadh.2013.09.006

[19] Czech Z., Butwin A., Głuch U., Kabatc J.: Influence of selected photoinitiators on important properties of photoreactive acrylic pressure-sensitive adhesives. Journal of Applied Polymer Science, 123, 118-123 (2012). https://doi.org/10.1002/app.34445

[20] Park C-H., Lee S-J., Lee T-H., Kim H-J.: Characterization of an acrylic polymer under hygrothermal aging as an optically clear adhesive for touch screen panels. International Journal of Adhesion and Adhesives, 63, 137-144 (2015).

https://doi.org/10.1016/j.ijadhadh.2015.08.012

[21] Everaerts A. I., Xia J.: Indium-tin-oxide compatible optically clear adhesive. U.S. Patent 20090087629 , USA (2009).

[22] Senthilkumar M., Mathiyarasu J., Joseph J., Phani K. L. N., Yegnaraman V.: Electrochemical instability of indium tin oxide (ITO) glass in acidic $\mathrm{pH}$ range during cathodic polarization. Materials Chemistry and Physics, 108, 403-407 (2008). https://doi.org/10.1016/j.matchemphys.2007.10.030

[23] Bejitual T. S., Ramji K., Kessman A. J., Sierros K. A., Cairns D. R.: Corrosion of an amorphous indium tin oxide film on polyethylene terephthalate at low concentrations of acrylic acid. Materials Chemistry and Physics, 132, 395-401 (2012).

https://doi.org/10.1016/j.matchemphys.2011.11.043 
[24] Jiang X., Li S., Shao L.: Pushing $\mathrm{CO}_{2}$-philic membrane performance to the limit by designing semi-interpenetrating networks (SIPN) for sustainable $\mathrm{CO}_{2}$ separations. Energy and Environmental Science, 10, 1339 1344 (2017). https://doi.org/10.1039/C6EE03566C

[25] Maag K., Lenhard W., Löffles H.: New UV curing systems for automotive applications. Progress in Organic Coatings, 40, 93-97 (2000). https://doi.org/10.1016/S0300-9440(00)00144-2

[26] Allen N. S.: Photoinitiators for UV and visible curing of coatings: Mechanisms and properties. Journal of Photochemistry and Photobiology A: Chemistry, 100, 101107 (1996).

https://doi.org/10.1016/S1010-6030(96)04426-7

[27] Nason C., Roper T., Hoyle C., Pojman J. A.: UV-induced frontal polymerization of multifunctional (meth) acrylates. Macromolecules, 38, 5506-5512 (2005). https://doi.org/10.1021/ma048569y

[28] Bennett A. W., Watts D. C.: Performance of two blue light-emitting-diode dental light curing units with distance and irradiation-time. Dental Materials, 20, 72-79 (2004). https://doi.org/10.1016/S0109-5641(03)00070-8

[29] Chattopadhyay D. K., Panda S. S., Raju K. V. S. N.: Thermal and mechanical properties of epoxy acrylate/ methacrylates UV cured coatings. Progess in Organic Coatings, 54, 10-19 (2005).

https://doi.org/10.1016/j.porgcoat.2004.12.007
[30] Joo H-S., Park Y-J., Do H-S., Kim H-J., Song S-Y., Choi K-Y.: The curing performance of UV-curable semi-interpenetrating polymer network structured acrylic pressure-sensitive adhesives. Journal of Adhesion Science and Technology, 21, 575-588 (2007). https://doi.org/10.1163/156856107781192346

[31] Nakamura Y., Imamura K., Yamamura K., Fujii S., Urahama Y.: Influence of crosslinking and peeling rate on tack properties of polyacrylic pressure-sensitive adhesives. Journal of Adhesion Science and Technology, 27, 1951-1965 (2013). https://doi.org/10.1080/01694243.2013.766564

[32] Lim D-H., Do H-S., Kim H-J.: PSA performances and viscoelastic properties of SIS-based PSA blends with H-DCPD tackifiers. Journal of Applied Polymer Science, 102, 2839-2846 (2006). https://doi.org/10.1002/app.24571

[33] Chung T-J., Park J-W., Lee H-J., Kwon H-J., Kim H-J., Lee Y-K., Tze W. T. Y.: The improvement of mechanical properties, thermal stability, and water absorption resistance of an eco-friendly PLA/kenaf biocomposite using acetylation. Applied Sciences, 8, 376/1-376/13 (2018). https://doi.org/10.3390/app8030376

[34] Do H-S., Park Y-J., Kim H-J.: Preparation and adhesion performance of UV-crosslinkable acrylic pressure sensitive adhesives. Journal of Adhesion Science and Technology, 20, 1529-1545 (2006). https://doi.org/10.1163/156856106778666462

[35] Asmussen E., Peutzfeldt A.: Two-step curing: Influence on conversion and softening of a dental polymer. Dental Materials, 19, 466-470 (2003). https://doi.org/10.1016/S0109-5641(02)00091-X 